N.K. Batchu, T. Vander Hoogerstraete, D. Banerjee, K. Binnemans

Separation and Purification Technology 174, 544-553 (2017).

Non-aqueous solvent extraction of rare-earth

nitrates from ethylene glycol to $n$-dodecane by

\title{
Cyanex 923
}

Nagaphani Kumar Batchu, ${ }^{\mathrm{a}}$ Tom Vander Hoogerstraete, ${ }^{\mathrm{a}}$ Dipanjan Banerjee, ${ }^{\mathrm{b}}$ and Koen Binnemans*,a

${ }^{a}$ KU Leuven, Department of Chemistry, Celestijnenlaan 200F, B-3001 Leuven (Belgium).

bDutch-Belgian Beamline (DUBBLE), ESRF - The European Synchrotron, CS 40220, F-38043 Grenoble Cedex 9, France

* Corresponding author

E-mail: Koen.Binnemans@kuleuven.be

Phone: +3216327446 


\begin{abstract}
A solvent extraction process comprising two immiscible organic phases has been developed for the extraction of rare earths. The more polar organic phase was ethylene glycol with dissolved rare-earth nitrate salts and lithium nitrate, while the less polar phase was a solution of the neutral extractant Cyanex ${ }^{\circledR} 923$ dissolved in $n$-dodecane. The solvent extraction mechanism was determined by slope analysis and the main species in the organic phase was identified by Extended X-ray Absorption Fine Structure (EXAFS) studies. The extraction from the ethylene glycol solution was compared with extraction from an aqueous feed solution. When compared to aqueous feed solutions, the light rare-earth elements (LREEs) are less efficiently extracted and the heavy rare-earth elements (HREEs) more efficiently extracted from an ethylene glycol feed solutions, resulting into the easy separation of HREEs from LREEs. The separation factors between neighboring elements are higher for this nonaqueous solvent extraction process than for extraction from an aqueous feed solution.
\end{abstract}

\title{
KEYWORDS:
}

Immiscible organic solvents; non-aqueous solvent extraction; solvometallurgy; rare earths; Cyanex 923 


\section{Introduction}

Solvent extraction (SX) is an important technique in hydrometallurgy for the separation and purification of metals, such as the rare earths (REEs), platinum group metals (PGMs), cobalt, nickel, copper and uranium [1]. In a solvent extraction process, metal ions are distributed between an aqueous phase and a water-immiscible organic phase. At equilibrium, the ratios of the concentrations of a metal ion in the organic phase and the aqueous phase depend on the nature of the metal ions, and differences in these ratios are the basis for the separation of a mixture of metals. Because all hydrometallurgical solvent extraction processes make use of an aqueous phase, one could get the impression that the presence of an aqueous phase is a requirement for solvent extraction. However, two mutually immiscible liquid phases are a sufficient condition. Liquid-liquid extraction from molten salts has been an active research field [2]. Different systems have been considered: (1) molten salt - molten salt; (2) molten salt - molten metal; (3) molten salt - organic solvent [3-10].

Recently, our research group has extended this approach of using molten salts to lowtemperature molten salts (ionic liquids) and has shown that two mutually immiscible ionic liquids can be efficient solvent extraction systems for cobalt-nickel separations [11] and for separation of mixtures of rare earths [12]. Foreman described the extraction of rare earths and transition metals from a deep-eutectic solvent (DES) based on choline chloride and lactic acid to an organic phase by Aliquat 336 or bis(2-ethylhexyl)phosphoric acid [13]. Only few examples of separation of metal ions by solvent extraction with two mutually immiscible molecular organic solvents can be found in the literature. Larsen and Trevorrow investigated the distribution of $\mathrm{ZrCl}_{4}$ and $\mathrm{HfCl}_{4}$ between acetonitrile and isoamyl ether [14]. Florence and Farrar studied the solvent extraction of $\mathrm{Ni}(\mathrm{II})$ from an anhydrous methanol solution 
containing a high concentration of lithium halide salts by long-chain amines [15]. Burns and Cattrall described the distribution of $\mathrm{Cu}(\mathrm{II})$ between methanolic $\mathrm{LiCl}$ solutions and benzene solutions of bis(3,5,5-trimethylhexyl)ammonium chloride [16]. Dean and Eskew used a methylisobutyl ketone/formamide two-phase system for the separation of Tl(III) from $\mathrm{Ga}(\mathrm{III}), \mathrm{In}(\mathrm{III}), \mathrm{Fe}(\mathrm{III}), \mathrm{Sn}(\mathrm{II})$ and $\mathrm{Sn}(\mathrm{IV})$ [17]. In the latter study the non-aqueous biphasic system was used for selective stripping of $\mathrm{Tl}(\mathrm{III})$ with a $1.5 \mathrm{M} \mathrm{HBr}$ solution in formamide after extraction to the methylisobutyl ketone (MIBK) phase, rather than for selective extraction. Matsui et al. studied the non-aqueous extraction of $\mathrm{Zn}(\mathrm{II})$ by trioctylphosphine oxide dissolved in toluene from an ethylene glycol solution containing $\mathrm{LiCl}$ [18]. Nonaqueous solvent extraction can offer some advantages compared to conventional solvent extraction with an aqueous feed phase. The mechanism for extraction from a non-aqueous solution might be different from that for extraction from an aqueous solution and this difference could be exploited to develop new, highly selective separation processes. Additionally, non-aqueous solvent extraction can be used for metal ions or metal complexes that have a strong tendency to hydrolyze in water.

The solvent pairs for non-aqueous solvent extraction must fulfil the following conditions: (1) formation of two phases upon mixing and low mutual solubility of the solvents; (2) fast phase separation after mixing (= short phase disengagement time); (3) the extractant must be soluble in the less polar phase; (4) the starting metal compounds or salts must be soluble in the more polar phase and the extracted metal complexes in the less polar phase; (5) the metal compounds must not react with the organic solvents. The first condition is the most difficult to fulfil because many organic solvents are mutually miscible. Several guidelines are available for the initial selection of solvent pairs, such as reported miscibility data [19], the 
Hildebrand solubility parameter $\delta$ for solvents [20] and the mixotropic series [21]. Especially the mixotropic series is a useful tool: the further two solvents are apart in the series, the lesser is the mutual solubility.

In this paper, we show that replacement of water in a solvent extraction process by the polar organic solvent ethylene glycol allows to design a selective process for group separation of heavy rare earths (HREEs) from light rare earths (LREEs). The rare earths are extracted from an ethylene glycol phase with dissolved $\mathrm{LiNO}_{3}$ by the extractant Cyanex ${ }^{\circledR} 923$ dissolved in $n$-dodecane. Cyanex ${ }^{\circledR} 923$ was selected as extractant because it is known that this neutral extractant can efficiently extract rare-earth ions from aqueous nitrate solutions, but not from aqueous chloride solutions [22-27]. Cyanex ${ }^{\circledR} 923$ is a commercially available extractant that consists of a mixture of four trialkylphosphine oxides: $\mathrm{R}_{3} \mathrm{P}=\mathrm{O}, \mathrm{R}_{2} \mathrm{R}{ }^{\prime} \mathrm{P}=\mathrm{O}$, $\mathrm{RR}^{\prime}{ }_{2} \mathrm{P}=\mathrm{O}$ and $\mathrm{R}_{3}{ }_{3} \mathrm{P}=\mathrm{O}$, where $\mathrm{R}=n$-octyl and $\mathrm{R}^{\prime}=n$-hexyl, and its average molecular mass is $348 \mathrm{~g} \mathrm{~mol}^{-1}[28,29]$. It is completely miscible with most organic diluents and gives a fast phase disengagement.

\section{Materials and methods}

\subsection{Materials and reagents}

$\mathrm{Nd}\left(\mathrm{NO}_{3}\right)_{3} \cdot 6 \mathrm{H}_{2} \mathrm{O}(99.9 \%)$ and $\mathrm{La}\left(\mathrm{NO}_{3}\right)_{3} \cdot 6 \mathrm{H}_{2} \mathrm{O}(99.9 \%)$ were purchased from Alfa Aesar

(Ward Hill, USA), $\mathrm{Ce}\left(\mathrm{NO}_{3}\right)_{3} \cdot 6 \mathrm{H}_{2} \mathrm{O}(99.9 \%)$ from Sigma-Aldrich (Diegem, Belgium),

$\operatorname{Pr}\left(\mathrm{NO}_{3}\right)_{3} \cdot 6 \mathrm{H}_{2} \mathrm{O}(99.9 \%), \mathrm{Gd}\left(\mathrm{NO}_{3}\right)_{3} \cdot 6 \mathrm{H}_{2} \mathrm{O}(99.9 \%), \mathrm{Dy}\left(\mathrm{NO}_{3}\right)_{3} \cdot 6 \mathrm{H}_{2} \mathrm{O}(99.9 \%)$, and $\mathrm{Yb}\left(\mathrm{NO}_{3}\right)_{3} \cdot 6 \mathrm{H}_{2} \mathrm{O}(99.9 \%)$ from Strem Chemicals (USA). $\mathrm{LiNO}_{3}(99 \%)$ was obtained from Sigma-Aldrich (Diegem, Belgium), while $n$-dodecane (>99\%) and ethylene glycol (99.9\%) 
were purchased from Acros Organics (Geel, Belgium). Cyanex ${ }^{\circledR} 923$ and bis(2,4,4dimethylpentyl phosphinic acid (Cyanex $\left.{ }^{\circledR} 272\right)$ were provided by Cytec Industries (Canada). Tri- $n$-butylphosphate (TBP) was obtained from Alfa Aesar (USA). A silicone solution in isopropanol (SERVA, Electrophoresis GmbH, Heidelberg, Germany) was used to siliconize the TXRF carriers. The gallium standard was purchased from Chem-Lab NV (Zedelgem, Belgium). All other chemicals used were of analytical grade.

\subsection{Instrumentation}

A benchtop total reflection X-ray fluorescence (TXRF) spectrometer (S2 Picofox model, Bruker) was used to determine the metal concentrations. Batch-mode extraction experiments were carried out by mixing two phases using flat magnetic stirrer (MIX 15 eco model, 2mag magnetic e motion). A Heraeus Megafuge 1.0 was used to centrifuge the samples after equilibrium. The water content was determined by coulometric Karl Fischer titration using a Mettler-Toledo DL39 titrator. The ${ }^{1} \mathrm{H}$ NMR spectra were recorded on a Bruker Avance 300 spectrometer (operating at $300 \mathrm{MHz}$ ). ${ }^{31} \mathrm{P}$ NMR spectra were recorded on a Bruker Ascend 400 spectrometer operating at $162 \mathrm{MHz}$. Acetone- $d_{6}$ was used as a solvent for NMR samples. The spectra were analyzed with SpinWorks software. The chemical shifts are noted in parts per million (ppm), referenced to tetramethylsilane for ${ }^{1} \mathrm{H}$ and to $85 \% \mathrm{H}_{3} \mathrm{PO}_{4}$ (external reference) for ${ }^{31} \mathrm{P}$ NMR. The Fourier Transform Infrared (FTIR) spectrum was recorded by a Bruker Vertex 70 spectrometer via the attenuated total reflectance (ATR) technique with a Bruker Platinum ATR accessory. The FTIR spectra was analyzed by OPUS software package. An Anton Paar rolling-ball viscometer (Lovis $2000 \mathrm{ME}$ ) was used for measuring the viscosity of ethylene glycol. A gas chromatograph, combined with a flame ionization detector 
(GC-FID) and Turbomatrix 16 headspace autosampler (HS) (Perkin Elmer, USA) was used for the determination of ethylene glycol concentration in $n$-dodecane samples. A Perkin Elmer CP-SIL 8 CB (5\%-phenyl-95\%-dimethylpolysiloxane) capillary column, $50 \mathrm{~m}$ long, $0.32 \mathrm{~mm}$ I.D. and $1.20 \mathrm{~m}$ film thickness was used as GC column. The peak area was determined by the PE TotalChrom Version 6.3.2.0646 software package.

\subsection{Solubility studies}

The mutual solubility experiments were carried out by mixing equal volumes $(5 \mathrm{~mL})$ of ethylene glycol and $n$-dodecane phases for $30 \mathrm{~min}$. After equilibrium, both phases were separated by centrifuging at $3000 \mathrm{rpm}$ for $5 \mathrm{~min}$. The experiments were conducted as a function of nitrate ion concentration and metal ion concentration in ethylene glycol phase and as a function of extractant concentration in the $n$-dodecane phase. The objective was to determine the solubility of Cyanex ${ }^{\circledR} 923$ in the ethylene glycol phase and to check the solubility/co-extraction of ethylene glycol to Cyanex ${ }^{\circledR} 923 / n$-dodecane phase. The solubility of Cyanex ${ }^{\circledR} 923$ in the ethylene glycol phase was identified using ${ }^{31} \mathrm{P}$ NMR studies and the solubility of ethylene glycol was estimated by GC-FID.

\subsection{EXAFS measurements}

Extended X-ray Absorption Fine Structure (EXAFS) spectra of the Nd L3-edge (6213 eV) were collected at the Dutch-Belgian Beamline (DUBBLE, BM26A) at the European Synchrotron Radiation Facility (ESRF) in Grenoble (France). The energy of the X-ray beam was tuned by a double-crystal monochromator operating in fixed-exit mode using a $\mathrm{Si}(111)$ 
crystal pair. The measurements were done in transmission mode using $\mathrm{Ar} / \mathrm{He}$ gas-filled ionization chambers at ambient pressure. A brass sample holder with Kapton ${ }^{\circledR}$ windows and a flexible polymeric spacer $\left(\mathrm{VITON}^{\circledR}\right)$ with a thickness of $1 \mathrm{~mm}$ was used as a sample holder.

Standard procedures were used for pre-edge subtraction and data normalization to isolate the EXAFS function $(\chi)$. The isolated EXAFS oscillations, accomplished by a smoothing spline as realized in the software program Viper [30], were $k^{4}$-weighted and Fourier transformed over the $k$ range from 3.14 to $11.04 \AA^{-1}$ and from 2.85 to $8.96 \AA^{-1}$ for $\mathrm{Nd}$ present in the ethylene glycol and $n$-dodecane phase, respectively. The data were fitted using the ab initio code FEFF 7.0 [31], which was used to calculate the theoretical phase and amplitude functions that were subsequently used in the non-linear least-squares refinement of the experimental data. Fitting of the model was performed in $R$ space between 0 and $4 \AA$ and 0 and $4.31 \AA$ for Nd present in the ethylene glycol and $n$-dodecane phase, respectively. Estimated standard deviations are shown between parentheses and calculated by VIPER. $S_{0}$ was fixed at 1.1 and calibrated after dissolving $\mathrm{NdCl}_{3}$ in a $1: 1$ molar ratio in Aliquat ${ }^{\circledR} 336$ and drying the mixture for 1 day at a Schlenk line at $110^{\circ} \mathrm{C}$.

\subsection{Solvent extraction procedure}

Solvent extraction experiments were performed by mixing equal volumes of the two phases, i.e. an aqueous solution and Cyanex ${ }^{\circledR} 923$ in $n$-dodecane for conventional solvent extraction and ethylene glycol and Cyanex ${ }^{\circledR} 923$ in $n$-dodecane for non-aqueous solvent extraction, in glass vials using a magnetic stirrer at $1200 \mathrm{rpm}$ and room temperature $(293 \pm 2 \mathrm{~K})$ for 15 
min, unless otherwise specified. After equilibrium, the phase separation was accelerated by centrifugation for $2 \mathrm{~min}$ at $3000 \mathrm{rpm}$ to make sure that no remains of either phases left in the other phase, even though phase disengagement was fast. The concentration of the rare earths in ethylene glycol was determined by TXRF spectrometer after adding a gallium internal standard. Praseodymium was used as internal standard for the experiments with $\mathrm{Nd}(\mathrm{III})$. The concentrations of the rare earths in the $n$-dodecane phase were obtained by the difference between the rare-earth concentration in the feed and the raffinate. The quartz glass sample carriers for TXRF measurements were pretreated with $20 \mu \mathrm{L}$ of a silicone solution in isopropanol and dried in oven for $2 \mathrm{~min}$ at $333 \mathrm{~K}$. Then, a sample of $2 \mu \mathrm{L}$ was added to carrier and dried at $333 \mathrm{~K}$. for $20 \mathrm{~min}$. The samples were measured for $300 \mathrm{~s}$ in TXRF spectrometer. All samples were measured in duplicate.

The distribution ratio $D$ is defined as the ratio of the total concentration of a compound $M$ in the less polar organic phase $\left(c_{\mathrm{solv} 2}\right)$ to the total concentration of the compound in the more polar organic phase $\left(c_{\mathrm{solv} 1}\right)$ :

$$
D=\frac{c_{\text {solv } 2}}{c_{\text {solv } 1}}
$$

For two substances $M_{A}$ and $M_{B}$, both distributed between the two organic phases, a separation factor $\beta$ can be defined (where $D_{A} \geq D_{B}$ ):

$$
\beta_{A, B}=\frac{D_{A}}{D_{B}}
$$


The closer this separation factor approaches to unity, the more extraction stages are required to separate the two substances. The percentage extraction $\% E[32,33]$ is calculated as follows:

$$
\% E=\frac{\mathrm{v}_{\text {solv } 2}\left[\mathrm{M}_{\text {solv } 2}\right]}{\mathrm{v}_{\text {solv } 2}\left[\mathrm{M}_{\text {solv } 2}\right]+\mathrm{V}_{\text {solv } 1}\left[\mathrm{M}_{\text {solv } 1}\right]} \times 100
$$

where $V_{\text {solv } 2}$ and $V_{\text {solv } 1}$ are the volumes of the less polar ( $n$-dodecane) and the more polar (ethylene glycol) organic phase, respectively. $\left[M_{\text {solv2 } 2}\right]$ and $\left[M_{s o l v 1}\right]$ are the concentrations of $M$ in the less and the more polar organic phase, respectively.

\section{Results and discussion}

\subsection{Mutual solubility of the organic phases}

The solvent pair ethylene glycol/ $n$-dodecane was identified as a promising system for nonaqueous solvent extraction, because test tube experiments indicated that two phases are formed by mixing equal volumes of these two solvents and that no significant volume changes occurred. The nitrate concentration in the ethylene glycol phase could be adjusted by

addition of anhydrous $\mathrm{LiNO}_{3}$. This salt was selected because of its good solubility in ethylene glycol. It is possible to prepare a $5 \mathrm{M} \mathrm{LiNO}_{3}$ solution in ethylene glycol. Saturation was observed above $5 \mathrm{M} \mathrm{LiNO} 3$.

The mutual solubility of ethylene glycol and $n$-dodecane was measured by recording the ${ }^{1} \mathrm{H}$ NMR spectra of both phases after equilibrium. It was found that ethylene glycol and $n$ dodecane were completely immiscible. The ${ }^{1} \mathrm{H}$ NMR spectra of both phases after equilibrium revealed that no resonance lines corresponding to ethylene glycol were found in the $n$ - 
dodecane phase and also no $n$-dodecane was observed in the ethylene glycol phase. In the second step, the mutual solubilities were determined as a function of Cyanex ${ }^{\circledR} 923$ concentration. ${ }^{31} \mathrm{P}$ NMR spectra of ethylene glycol after equilibrium with Cyanex ${ }^{\circledR} 923$ indicated no solubility of Cyanex ${ }^{\circledR} 923$ owing to the absence of resonance lines corresponding to the $\mathrm{P}=\mathrm{O}$ group in ethylene glycol phase. This means that there is no loss of extractant during the solvent extraction experiments. The solubility of ethylene glycol in Cyanex $^{\circledR} 923 / n$-dodecane was estimated by GC-FID. It was found that about $24.5 \mathrm{~g} \mathrm{~L}^{-1}$ of ethylene glycol was co-extracted into $1 \mathrm{M}$ Cyanex ${ }^{\circledR}$ 923. In the third step, the solubility of Cyanex ${ }^{\circledR} 923$ in the ethylene glycol was studied as a function of $\mathrm{LiNO}_{3}$ concentration and $\mathrm{La}(\mathrm{III})$ concentration. In none of the experiments, there is loss of Cyanex ${ }^{\circledR} 923$ to the ethylene glycol phase as indicated by ${ }^{31} \mathrm{P}$ NMR spectra. The co-extracted ethylene glycol content in Cyanex 923 decreased to $20.8 \mathrm{~g} \mathrm{~L}^{-1}$ by addition of $1 \mathrm{M} \mathrm{LiNO}_{3}$ and $10 \mathrm{~g} \mathrm{~L}^{-1}$ of La(III) to the ethylene glycol phase. However, the co-extraction of ethylene glycol could be controlled by pre-saturating the Cyanex ${ }^{\circledR} 923$ with ethylene glycol. This is common practice for solvating extractants like Cyanex ${ }^{\circledR} 923$ which can extract acids/water in conventional solvent extraction experiments.

The viscosity of ethylene glycol was measured as a function of the $\mathrm{LiNO}_{3}$ concentration. The viscosity of ethylene glycol increased gradually with increasing the $\mathrm{LiNO}_{3}$ concentration from $22 \mathrm{mPa} . \mathrm{s}$ for a $0.5 \mathrm{M}$ solution to $112 \mathrm{mPa} . \mathrm{s}$ for a $5 \mathrm{M}$ solution (at room temperature). The measurement of the influence of temperature on the viscosity of ethylene glycol (+1 $\left.\mathrm{M} \mathrm{LiNO}_{3}\right)$ indicated that the viscosity gradually decreased with increase in temperature to $11 \mathrm{mPa} \cdot \mathrm{s}$ at $323 \mathrm{~K}$. 


\subsection{Selection of extractant}

Solvent extraction of $\mathrm{Nd}(\mathrm{III})$ from ethylene glycol (+1 $\left.\mathrm{M} \mathrm{LiNO}_{3}\right)$ was carried out using Cyanex ${ }^{\circledR} 923$, Cyanex ${ }^{\circledR} 272$ and TBP in $n$-dodecane in order to find the suitable extractant (Figure 1). The structures of the three extractants are given in Scheme 1. It was observed that Cyanex $^{\circledR} 923$ showed good extraction capacity towards Nd(III). The extraction capacity of Cyanex $^{\circledR} 923$ was far greater than Cyanex ${ }^{\circledR} 272$ and TBP. The extraction order can be given as follows: Cyanex ${ }^{\circledR} 923>>$ Cyanex $^{\circledR} 272>$ TBP. This can be explained on the basis of Gutmann donor number (DN) which is defined as the negative $\Delta H$ value of adduct formation between $\mathrm{SbCl}_{5}$ and an electron-pair donor solvent in dilute solutions in the non-coordinating solvent 1,2-dichloroethane [34]. The extraction power depends on the Gutmann donor number. The higher the donor number, the stronger is the interaction between a Lewis acidic metal complex and the donor solvent (a solvent with a dissolved donor molecule acting as the extractant). The metal extraction takes place from a solvent with a lower donor number to a solvent with a higher donor number. Phosphine oxides, which are present in Cyanex ${ }^{\circledR} 923$, are among the molecules with the highest donor number. $n$-Dodecane acts merely as a diluent and the extraction power is due to the phosphine oxide molecules. The donor number and the corresponding extractive power for phosphine oxides can be given as: $\mathrm{R}_{3} \mathrm{P}=\mathrm{O}>\mathrm{R}_{2}(\mathrm{OR}) \mathrm{P}=\mathrm{O}$ $>\mathrm{R}(\mathrm{OR})_{2} \mathrm{P}=\mathrm{O}>(\mathrm{RO}){ }_{3} \mathrm{P}=\mathrm{O}$. 


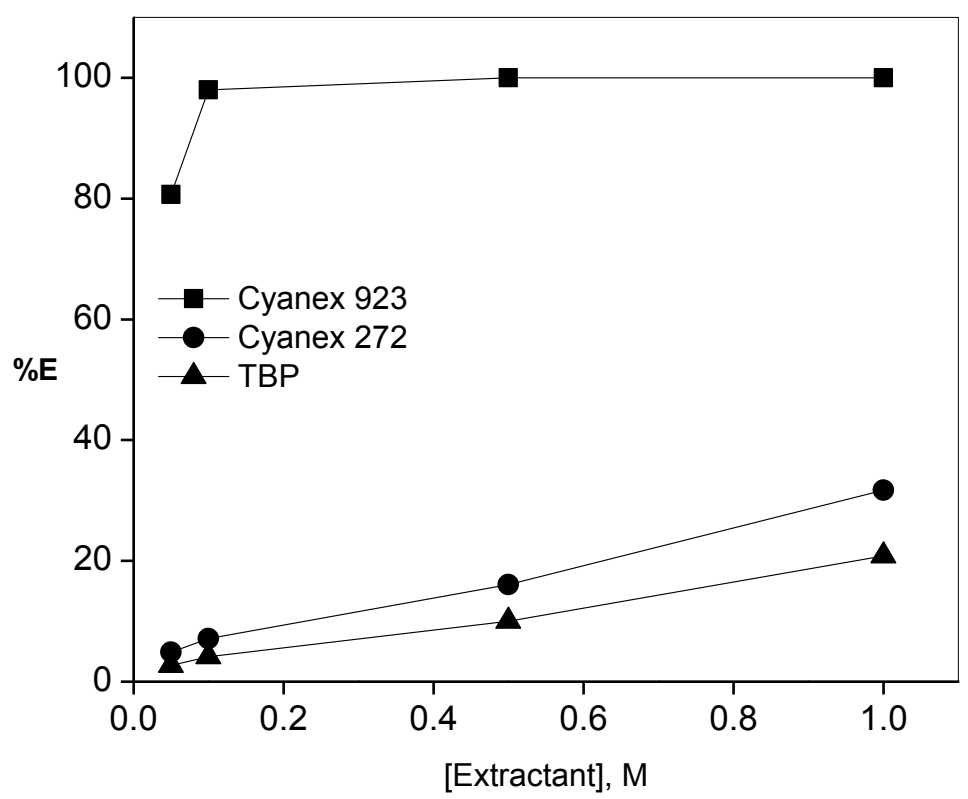

Figure 1. Influence of extractant concentration on the extraction of $\mathrm{Nd}(\mathrm{III}) .[\mathrm{Nd}(\mathrm{III})]=7.53$ $\times 10^{-3} \mathrm{M}$ in ethylene glycol, $\left[\mathrm{LiNO}_{3}\right]=1 \mathrm{M}, \mathrm{RT}$, equilibration time $=30 \mathrm{~min}$. 


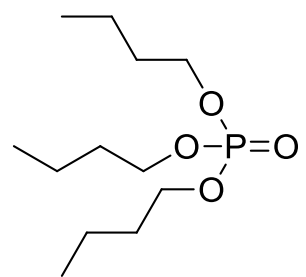

TBP

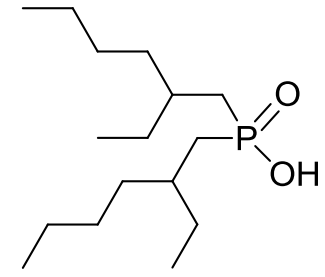

Cyanex 272

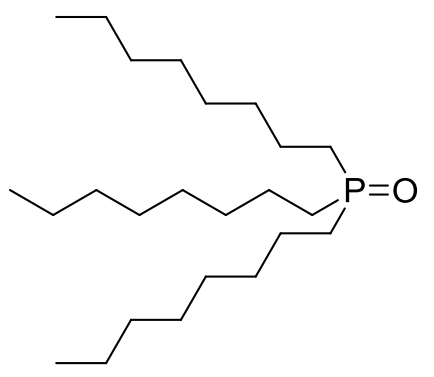

Cyanex 923

(main component)

Scheme 1. Structures of tri- $n$-butylphosphate (TBP), Cyanex ${ }^{\circledR} 272$ and Cyanex ${ }^{\circledR} 923$. For Cyanex $^{\circledR} 923$, the main component $\mathrm{R}_{3} \mathrm{P}=\mathrm{O}(\mathrm{R}=$ octyl) is shown. Other components include $\mathrm{R}_{2} \mathrm{R}^{\prime} \mathrm{P}=\mathrm{O}, \mathrm{RR}^{\prime}{ }_{2} \mathrm{P}=\mathrm{O}$ and $\mathrm{R}_{3} \mathrm{P}=\mathrm{O}\left(\mathrm{R}=\right.$ octyl, $\mathrm{R}^{\prime}=$ hexyl).

\subsection{Extraction of $\mathrm{Nd}(\mathrm{III})$}

The extraction of $\mathrm{Nd}(\mathrm{III})$ from ethylene glycol solution was studied as a first model system. It is important to determine the equilibration time while studying systems that are more viscous than conventional aqueous systems. Figure 2 shows the variation of $\% E$ as a function of the equilibration time. It was found that equilibrium was reached very fast, within 2 min. Prolonged equilibration times did not affect the $\% E$ value. However, to ensure that 
equilibrium was reached, all the subsequent experiments were carried out at an equilibration time of $15 \mathrm{~min}$.

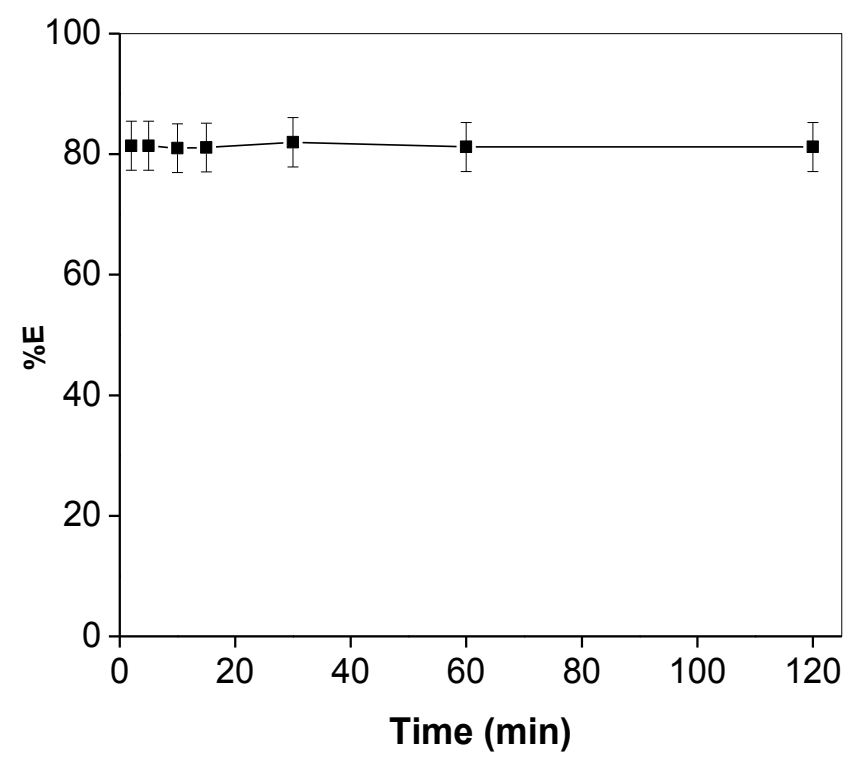

Figure 2. Effect of equilibration time on the extraction of $\mathrm{Nd}(\mathrm{III})$ from ethylene glycol. $[\mathrm{Nd}(\mathrm{III})]=6.07 \times 10^{-3} \mathrm{M}$ in ethylene glycol, $\left[\mathrm{LiNO}_{3}\right]=1 \mathrm{M},\left[\mathrm{Cyanex}^{\circledR} 923\right]=0.05 \mathrm{M}$ in $n-$ dodecane, RT.

The extraction of $\mathrm{Nd}(\mathrm{III})$ from ethylene glycol containing $1 \mathrm{MLiNO}_{3}$ was studied by varying the concentration of Cyanex ${ }^{\circledR} 923$. The percentage extraction of $\mathrm{Nd}(\mathrm{III})$ increased from 13.3 to $98.0 \%$ with increasing Cyanex ${ }^{\circledR} 923$ concentration $(0.01-0.1 \mathrm{M})$ as expected. Furthermore, a plot of $\log D$ versus $\log [$ Cyanex923] is a straight line with a slope of $2.85 \pm$ 0.16. This shows that three molecules of Cyanex ${ }^{\circledR} 923$ are involved in the extraction reaction (Figure 3). The extraction of $\mathrm{Nd}(\mathrm{III})$ by Cyanex ${ }^{\circledR} 923$ was studied as a function of the nitrate ion concentration in the ethylene glycol solution to investigate the effect of the salting-out 
agent (Figure 4). The $\% E$ of $\mathrm{Nd}$ (III) increased from 25.8 to 79.8 with an increase in the nitrate ion concentration from 0.1 to $1 \mathrm{M}$. This increase in $\% \mathrm{E}$ values is an indication for the participation of the nitrate ion in the extracted complex.

The IR spectra of loaded Cyanex ${ }^{\circledR} 923$ shows absorption bands at 1465, 1289, and 1028 $\mathrm{cm}^{-1}$ corresponding to vibrations of the coordinated nitrate ion in the Cyanex ${ }^{\circledR} 923 / n$ dodecane phase (Figure 5) $[35,36]$. The band at $1124 \mathrm{~cm}^{-1}$ can be assigned to the $\mathrm{P}=\mathrm{O}$ group in loaded Cyanex ${ }^{\circledR} 923$, which is shifted due to the coordination to the rare-earth ions from $1147 \mathrm{~cm}^{-1}$ in pure Cyanex ${ }^{\circledR} 923$. The bands at 2956, 2922 and $2853 \mathrm{~cm}^{-1}$ are due to C-H vibrations of $n$-dodecane. Note that ethylene glycol bands cannot be observed in the IR spectra of loaded Cyanex ${ }^{\circledR} 923 / n$-dodecane phase because of the low concentration of ethylene glycol. EXAFS measurements confirmed the presence of three nitrate ions in the primary coordination shell of $\mathrm{Nd}(\mathrm{III})$ in the organic phase, suggesting the species in the organic phase as $\mathrm{Nd}\left(\mathrm{NO}_{3}\right)_{3} \cdot 3 \mathrm{~L}$ (vide infra).

Based on these findings, it is suggested that $\mathrm{Nd}(\mathrm{III})$ is extracted as a neutral complex (neutral mechanism) with three coordinated Cyanex ${ }^{\circledR} 923$ molecules:

$$
\begin{aligned}
& \mathrm{Nd}^{3+}+3 E G \leftrightarrows N d(E G)_{3}^{3+} \\
& N d(E G)_{3}^{3+}+3 \mathrm{NO}_{3}^{-}+3 \bar{L} \leftrightarrows \overline{\mathrm{Nd}\left(\mathrm{NO}_{3}\right)_{3} 3 L \cdot E G}
\end{aligned}
$$

Here the bar represents a molecule in the $n$-dodecane phase and $L$ stands for a Cyanex 923 molecule. It must be mentioned that the stoichiometry of the extracted complex is the same as what is observed for extraction of rare-earth ions by Cyanex ${ }^{\circledR} 923$ and tri- $n$-butylphosphate (TBP) [37]. 


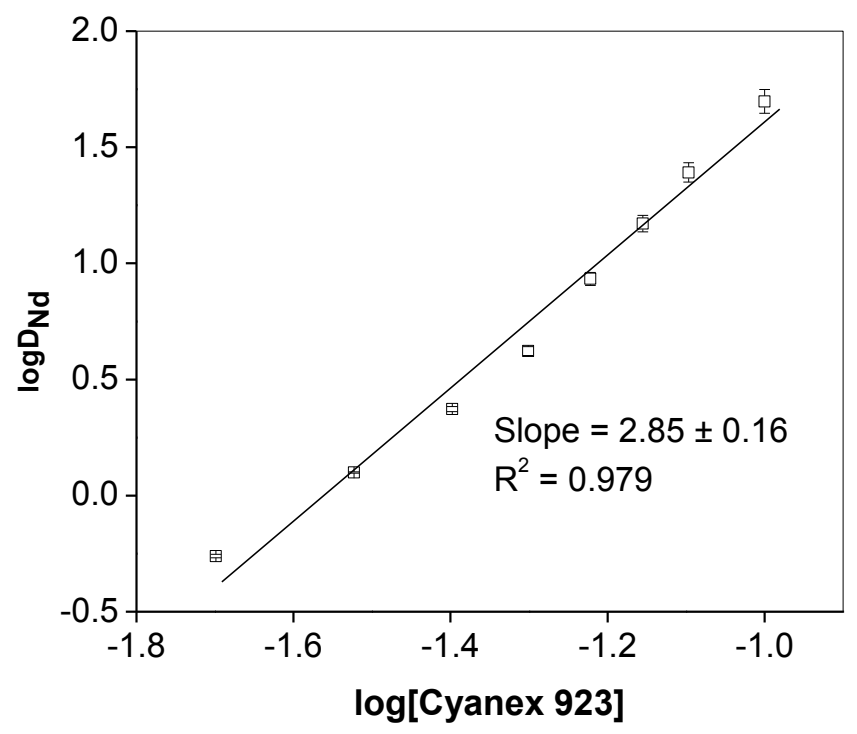

Figure 3. Variation of the distribution ratio of $\mathrm{Nd}(\mathrm{III})$ as a function of the Cyanex ${ }^{\circledR} 923$ concentration. $[\mathrm{Nd}(\mathrm{III})]=7.53 \times 10^{-3} \mathrm{M}$ in ethylene glycol, $\left[\mathrm{LiNO}_{3}\right]=1 \mathrm{M},\left[\mathrm{Cyanex}^{\circledR} 923\right]=$ $0.01-0.1 \mathrm{M}$ in $n$-dodecane, $\mathrm{RT}$, time $=30 \mathrm{~min}$.

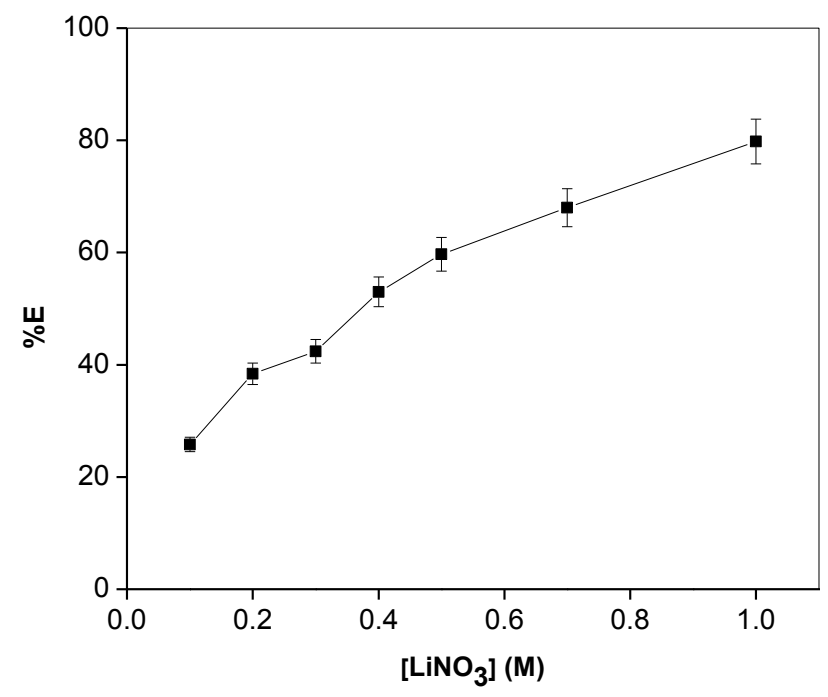


Figure 4. Variation of the $\% E$ of $\mathrm{Nd}(\mathrm{III})$ as a function of nitrate ion concentration.

Experimental conditions: $[\mathrm{Nd}(\mathrm{III})]=7.01 \times 10^{-3} \mathrm{M}$ in ethylene glycol, $\left[\mathrm{LiNO}_{3}\right]=0.1-1 \mathrm{M}$, $\left[\right.$ Cyanex $^{\circledR}$ 923] $=0.05 \mathrm{M}$ in $n$-dodecane.

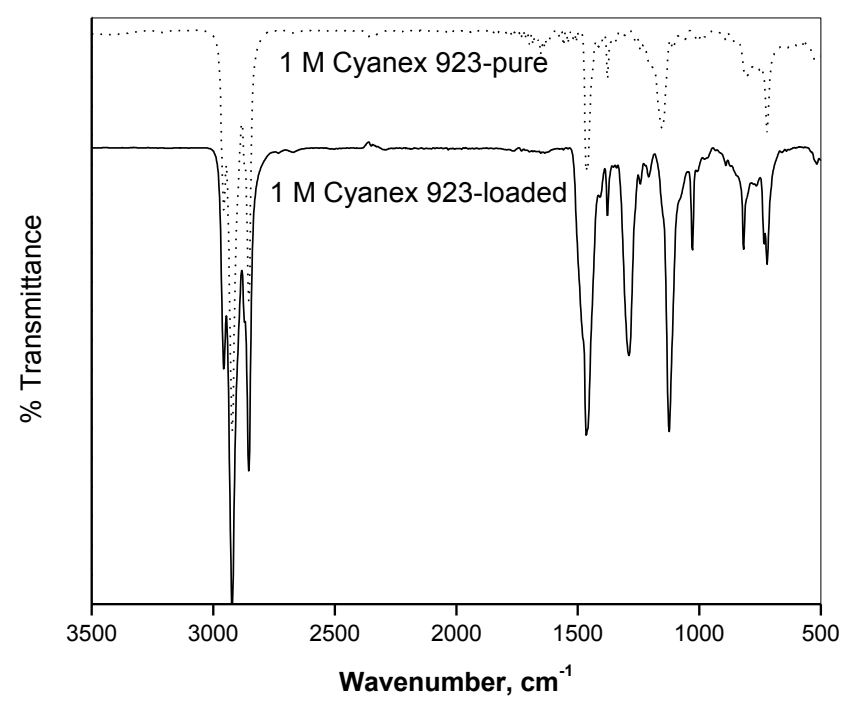

Figure 5. FTIR spectra of Cyanex ${ }^{\circledR} 923$ before and after loading with $\mathrm{Nd}(\mathrm{III})$.

\subsection{Speciation studies by EXAFS}

EXAFS analysis of the $\mathrm{Nd}(\mathrm{III})$ complex in the ethylene glycol phase showed close to nine coordinating oxygen atoms in the first shell positioned at two different positions (Fig. 6). This suggests a tricapped trigonal prism configuration, similar to the hydration of $\mathrm{Nd}(\mathrm{III})$ in water [38]. Therefore, the number of oxygen atoms was constrained to $6+3$ (Table 1). The fit resulted in two distances, three oxygen atoms are positioned at $2.616 \AA\left(\sigma^{2}=0.008 \AA^{2}\right)$ and 6 oxygens at $2.485 \AA\left(\sigma^{2}=0.009 \AA^{2}\right)$. The number of hydrogen atoms $(\mathrm{N}=12)$ was constrained to be twice the number of oxygen atoms at the shortest distance. Any fit including the three 
extra hydrogen atoms attached to the oxygen atoms of ethylene glycol at the capping position lead to impossible parameters for this path, which is due to the low contribution of these scattering atoms to the EXAFS function. A third shell of carbon atoms, was found at $3.469 \AA$ $\left(\sigma^{2}=0.008 \AA^{2}\right)$. If $N$ was allowed to vary, a degeneracy of 1.4 and a Debye Waller factor of $0.002 \AA^{2}$ was found, which is too low to be physically possible at room temperature. As both parameters are strongly correlated, the number of carbon atoms was constrained to three, giving a reasonable $\sigma^{2}$ of $0.008 \AA^{2}$. The carbon atoms were found at $3.469 \AA$, which results into a calculated $\mathrm{Nd}-\mathrm{O}-\mathrm{C}$ bond angle of $114^{\circ}$. A model with six carbon atoms resulted in a bad fit of the Nd-C scattering path suggesting as well monodentate ligating ethylene glycol molecules. This is remarkable as a bidentate coordination mode of ethylene glycol is more probable than a monodentate one $[39,40]$. A model that assumes monodentate coordinating nitrate ligands in the capping positions, results in a goodness of the fit which was higher $(8.9 \%)$ than in case of capping ethylene glycol molecules (8\%) and a higher $\sigma^{2}$ of $0.012 \AA^{2}$. Moreover, monodentate coordination of nitrate ions to trivalent rare-earth ions is very unlikely. Also a bidentate ligating nitrate ions could be excluded because the data are lacking the single and multiple scattering paths involving the furthest oxygen atom of nitrate. Therefore, it can be concluded that $\mathrm{Nd}(\mathrm{III})$ is coordinating to six water molecules on the corners of the prism and three monodentate ethylene glycol molecules at the capping positions. The stoichiometry of the $\mathrm{Nd}(\mathrm{III})$ complex can therefore be written as $\mathrm{Nd}\left(\mathrm{H}_{2} \mathrm{O}\right)_{6}(\mathrm{EG})_{3}$, where $\mathrm{EG}=$ ethylene glycol. 
Table 1. Selected degeneracies $(N)$, bond distances $(r)$ and Debye-Waller factors $\left(\sigma^{2}\right)$ for $\mathrm{Nd}\left(\mathrm{H}_{2} \mathrm{O}\right)_{6}(\mathrm{EG})_{3}$.

\begin{tabular}{llll}
\hline & $\mathrm{N}$ & $\mathrm{r}(\AA)$ & $\sigma^{2}\left(\AA^{2}\right)$ \\
\hline $\mathrm{Nd}-\mathrm{O}$ & 6 & $2.485(2)$ & $0.009(1)$ \\
$\mathrm{Nd}-\mathrm{O}$ & 3 & $2.616(1)$ & $0.008(1)$ \\
$\mathrm{Nd}-\mathrm{H}$ & 12 & $2.919(31)$ & $0.012(4)$ \\
$\mathrm{Nd}-\mathrm{C}$ & 3 & $3.469(12)$ & $0.008(2)$ \\
\hline
\end{tabular}
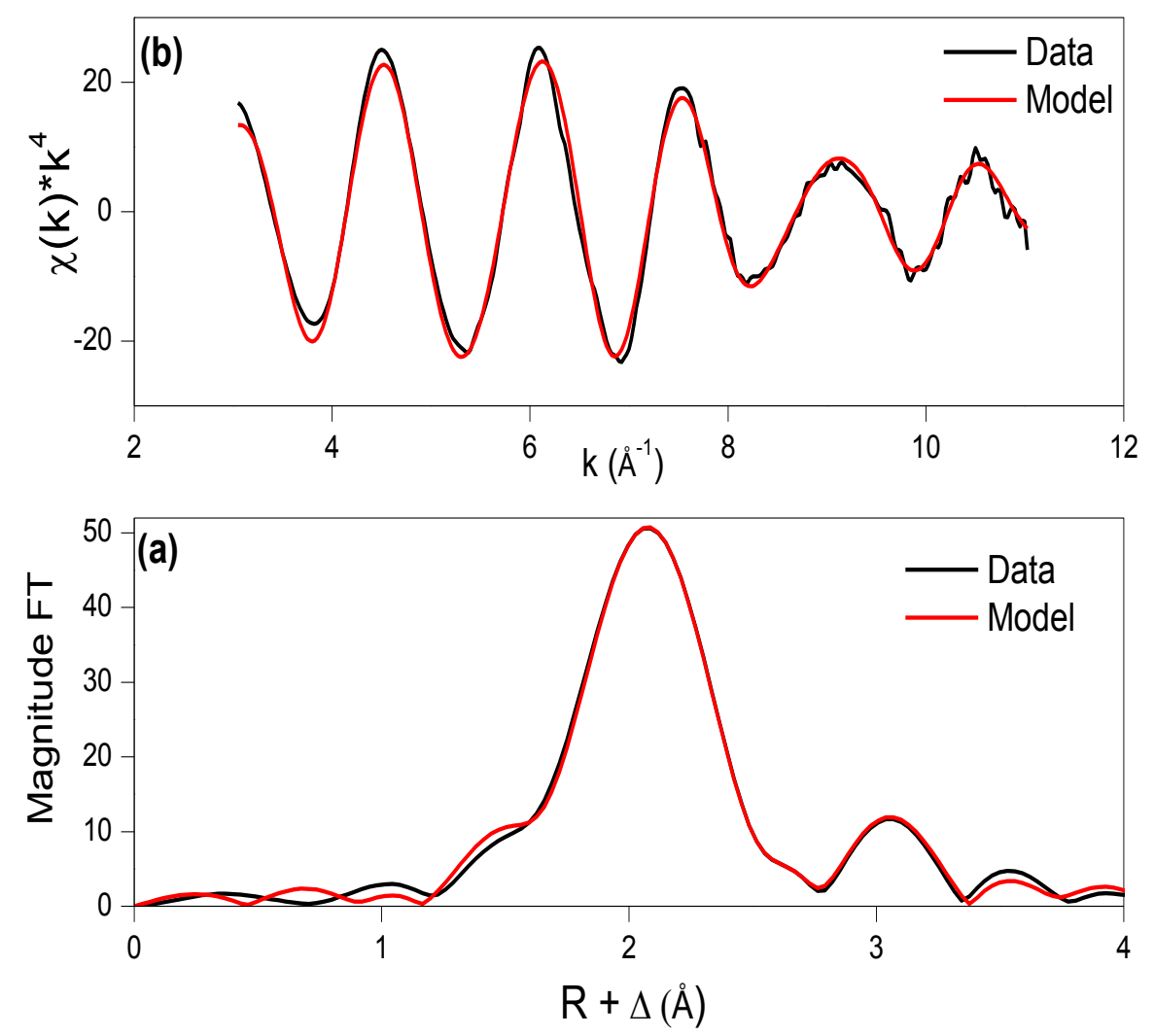

Figure 6. Fourier transform and fitted model of the EXAFS spectrum of $\mathrm{Nd}_{(}\left(\mathrm{H}_{2} \mathrm{O}\right)_{6}(\mathrm{EG})_{3}$ (a) and EXAFS function $\chi(\mathrm{k}) * \mathrm{k}^{4}$ and fitted model of $\mathrm{Nd}\left(\mathrm{H}_{2} \mathrm{O}\right)_{6}(\mathrm{EG})_{3}(\mathrm{~b})$. 
The EXAFS function of $\mathrm{Nd}$ present in the Cyanex ${ }^{\circledR} 923 / n$-dodecane phase was modelled based on the crystal structure of $\mathrm{Nd}\left(\mathrm{NO}_{3}\right)_{3}$ (tert-butylphosphine oxide $)_{2}$ found by Bowden et al. [41]. The sum of the single scattering paths to the closest oxygen atoms of the phosphine oxide and the nitrate anions was constrained to nine (Fig. 7). This coordination number was selected based on the assumption that three nitrates are coordinating and the fact that three coordinating phosphine oxides were found by slope analysis. This complex is than similar to the one found for the extraction of Ln from an aqueous solution [37]. The Debye-Waller factor were constrained to be above 0.008 , which is a reasonable value for this kind of backscatterers in the first shell (Table 2). From the crystal structure of $\mathrm{Nd}\left(\mathrm{NO}_{3}\right)_{3}($ tertbutylphosphine oxide)2, it can be concluded that the multiple scattering paths involving the phosphorus and the oxygen atoms of the phosphine oxide have almost of the same distances because of an Ln-O-P angle close to $180^{\circ}$. To reduce the number of free parameters and the strength of the fit, the Debye-Waller factors and the distances of the two, three and four leg scattering paths involving the phosphorus atoms (and bonded oxygen atom) were set to be equal. This results in a large Debye-Waller factor. The same constrains were made for the scattering paths involving the nitrogen and oxygen atoms of the nitrate anion. In this way, the number of free parameters was equal to 11 and there were 7 degrees of freedom. A fit of the data resulted in three bidentate coordinating nitrate anions and three phosphine oxide ligands. 
Table 2. Selected degeneracies $(N)$, bond distances $(r)$ and Debye-Waller factors $\left(\sigma^{2}\right)$ for the $\mathrm{Nd}(\mathrm{III})$ complex extracted by Cyanex ${ }^{\circledR} 923$ into the $n$-dodecane phase.

\begin{tabular}{lllll}
\hline & $\mathrm{N}$ & $\mathrm{r}(\AA)$ & $\sigma^{2}\left(\AA^{2}\right)$ & $\begin{array}{l}\text { Bond distance } \\
\text { in Ref. 39 for } \\
\mathrm{Nd}\end{array}$ \\
\hline $\mathrm{Nd} \mathrm{-} \mathrm{O}$ & $5.9(1)$ & $2.521(2)$ & $0.008(1)$ & 2.56 \\
$\mathrm{Nd} \mathrm{-} \mathrm{O}$ & $3.1(1)$ & $2.363(4)$ & $0.008(1)$ & 2.35 \\
\hline
\end{tabular}
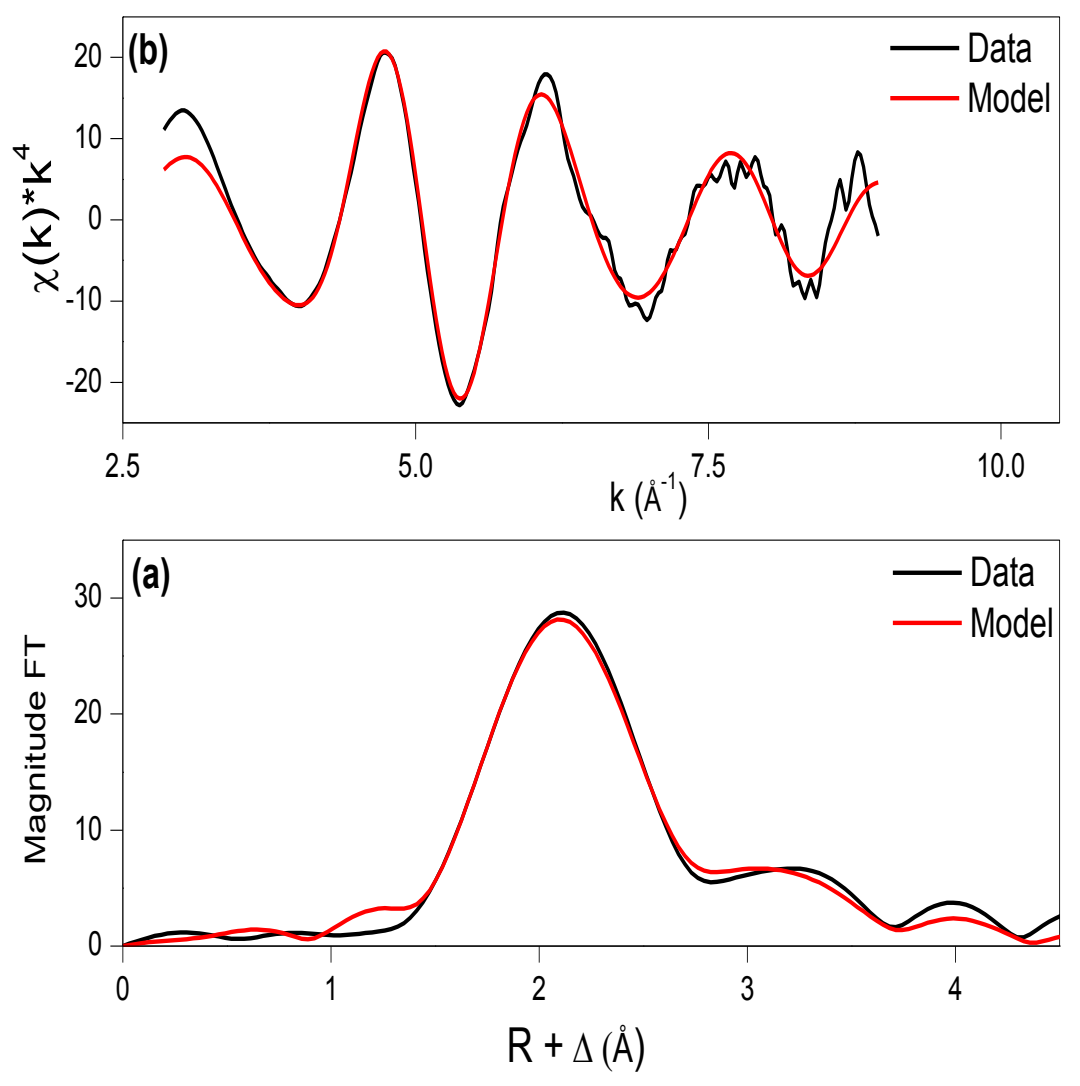
Figure 7. Fourier transform and fitted model of the EXAFS spectrum of $\mathrm{Nd}\left(\mathrm{NO}_{3}\right)_{3}\left(\mathrm{Cyanex}^{\circledR}\right.$ 923)3 (a) and EXAFS function $\chi(\mathrm{k})^{*} \mathrm{k}^{4}$ and fitted model of the EXAFS spectrum of $\mathrm{Nd}\left(\mathrm{NO}_{3}\right)_{3}\left(\text { Cyanex }^{\circledR} \text { 923) }\right)_{3}(\mathrm{~b})$.

\subsection{Thermodynamic parameters}

The extraction of $\mathrm{Nd}(\mathrm{III})$ by Cyanex ${ }^{\circledR} 923$ in $n$-dodecane from ethylene glycol was performed at temperatures ranging from $300 \mathrm{~K}$ to $333 \mathrm{~K}$, to determine the influence of the temperature on the extraction process. It was observed that the distribution ratio decreased with increasing temperature. The enthalpy of the extraction was derived from the slope of the plot of $\log D$ versus 1000/T $\left(\mathrm{K}^{-1}\right)$ using the Van 't Hoff equation [42]:

$$
\Delta H_{t o t}=\frac{-2.303 \mathrm{R} \Delta \log D}{\Delta(1 / T)}
$$

The enthalpy change during the extraction was found to be $-9.9 \mathrm{~kJ} \mathrm{~mol}^{-1}$, showing that the extraction process is exothermic (Figure 8). The change in Gibb's free energy $(\Delta G)$ can be calculated from equation (7):

$$
\Delta G=-2.303 \mathrm{R} T \log K_{e x}
$$

The average value of $\log K_{e x}$ was obtained from variation of extractant and nitrate ion concentrations. The value of $\Delta G$ was found to be $-29.8 \mathrm{kJmol}^{-1}$. This indicates that the process is energetically favored and spontaneous. The change in entropy $(\Delta S)$ at a fixed temperature can be evaluated using equation (8): 


$$
\Delta S=\frac{\Delta H-\Delta G}{T}
$$

The value of $\Delta S$ was determined to be $67.7 \mathrm{JK}^{-1} \mathrm{~mol}^{-1}$.

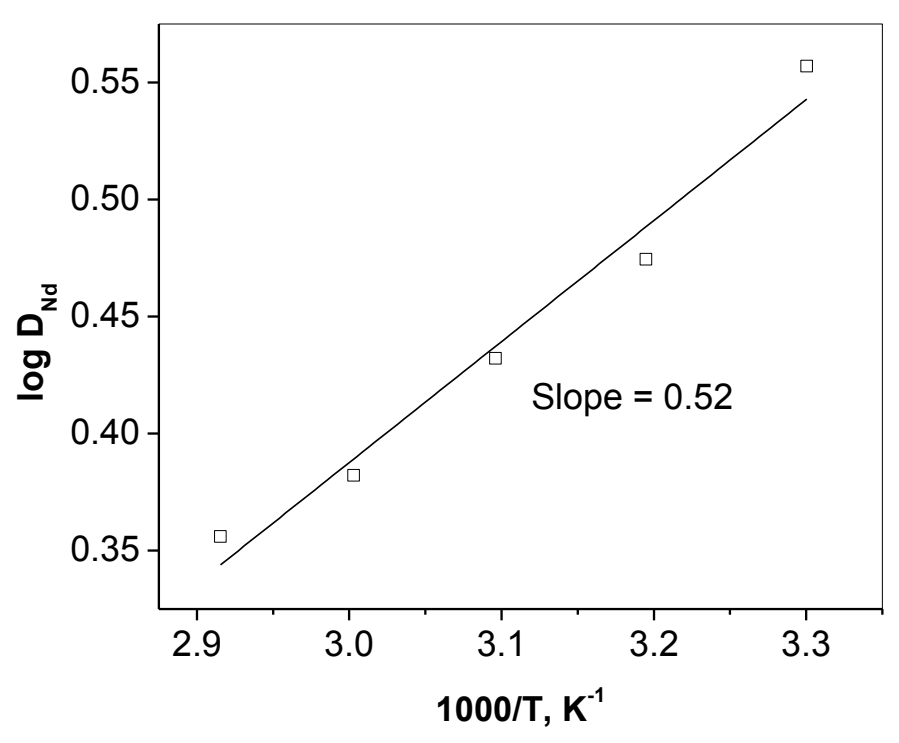

Figure 8. Influence of the temperature on the distribution ratio of $\mathrm{Nd}(\mathrm{III}) .[\mathrm{Nd}(\mathrm{III})]=6.7 \times$ $10^{-3} \mathrm{M}$ in ethylene glycol, $\left[\mathrm{LiNO}_{3}\right]=1 \mathrm{M},\left[\right.$ Cyanex $\left.^{\circledR} 923\right]=0.05 \mathrm{M}$, temperature $=303-343$ $\mathrm{K}, \mathrm{R}^{2}=0.967$.

\subsection{Effect of metal ion concentration}

The effect of metal concentration was investigated using a 0.05 M Cyanex ${ }^{\circledR} 923$ solution in $n$ dodecane by varying the metal concentration in the ethylene glycol phase. The $\% E$ decreased gradually with an increase in the metal concentration in the feed (Figure 9). The loading of Cyanex ${ }^{\circledR} 923$ increased with increasing in metal concentration in the feed up to $1430 \mathrm{mg} \mathrm{L}^{-1}$ 
and a plateau region corresponding to maximum loading was observed for higher metal concentration in the feed solution.
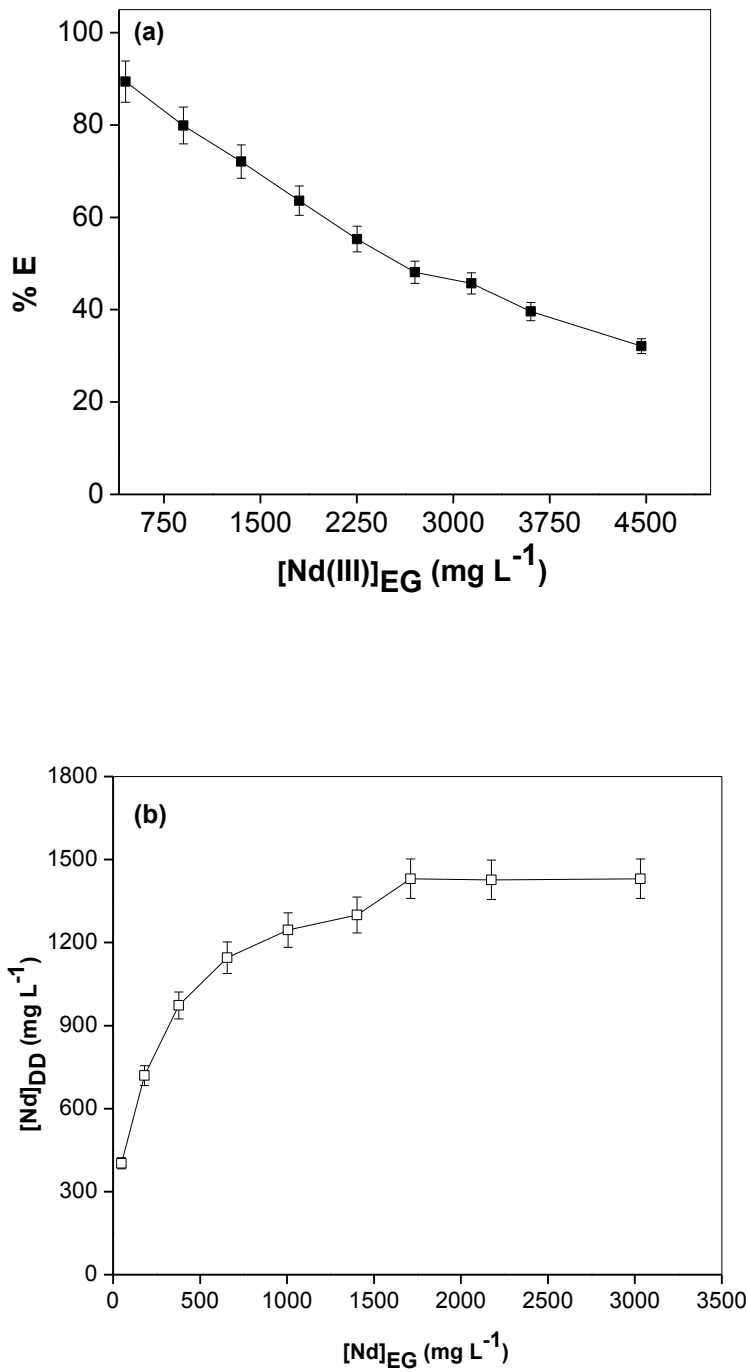

Figure 9. (a) Variation of the $\% E$ of $\mathrm{Nd}(\mathrm{III})$ as a function of the initial $\mathrm{Nd}(\mathrm{III})$ concentration in the ethylene glycol phase and (b) extraction isotherm of $\mathrm{Nd}(\mathrm{III})$. [Nd(III)]Feed $=450-4500 \mathrm{mg} \mathrm{L}^{-1},\left[\mathrm{LiNO}_{3}\right]=1 \mathrm{M},\left[\mathrm{Cyanex}{ }^{\circledR} 923\right]=0.05 \mathrm{M}$ in $n$-dodecane, $\mathrm{RT}$. 


\subsection{Influence of water}

The water content of ethylene glycol feed solution (containing the rare-earth salt) was 0.05 wt $\%$. Most of the water was introduced via the water of hydration of the hydrated rare-earth nitrate salts. To investigate the influence of larger quantities of water, water was gradually added to the $\mathrm{Nd}(\mathrm{III})$ feed solution. It was observed that the $\% E$ gradually increased as a function of the water concentration until 30\% (v/v) (Figure 10). For higher concentrations of water, the $\% E$ remained constant as a function of the water concentration. $\mathrm{Nd}(\mathrm{III})$ is less efficiently extracted from an ethylene glycol feed solution than from an aqueous feed solution. This can be explained on the basis of solvation of metal ions in non-aqueous solvents. The activity of cation is suppressed in the non-aqueous solvent environment and this leads to poor extraction of the metal ion to the less polar organic phase. These observation are similar to the results observed by Shibata et al. from the extraction of $\mathrm{Cu}(\mathrm{II})$ from mixed aqueous-organic solutions of DMSO by bis(2-ethylhexyl)phosphoric acid (D2EPHA) diluted in hexane [43]. 


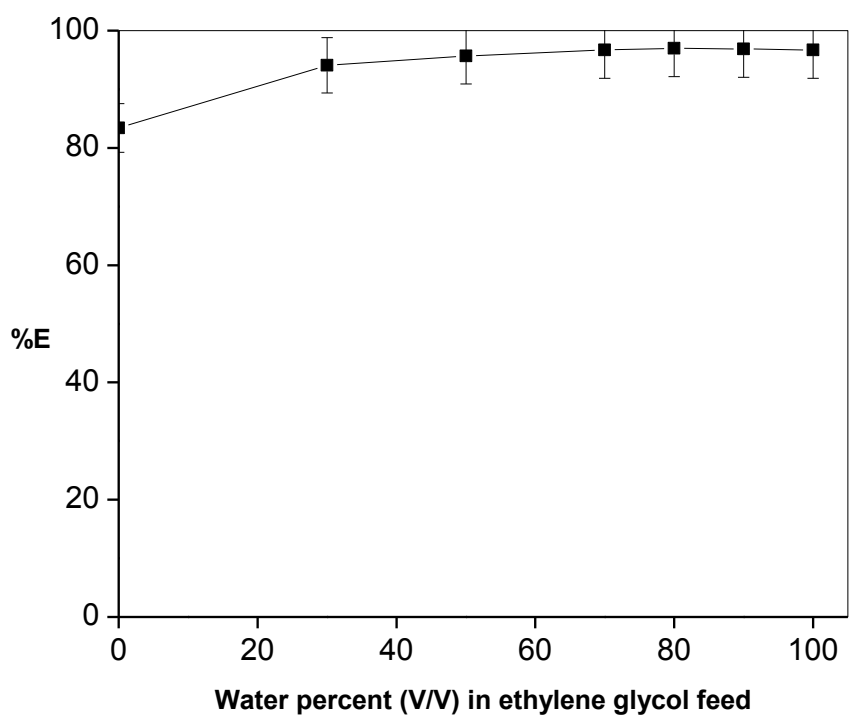

Figure 10. Influence of the water percent in ethylene glycol (EG) phase on the extraction of $\mathrm{Nd}(\mathrm{III})$ by Cyanex ${ }^{\circledR} 923$ in $n$-dodecane. $[\mathrm{Nd}(\mathrm{III})]=6.47 \times 10^{-3} \mathrm{M}, \mathrm{EG}=0-100 \%(\mathrm{v} / \mathrm{v})$, $\left[\mathrm{LiNO}_{3}\right]=1 \mathrm{M},\left[\right.$ Cyanex $\left.{ }^{\circledR} 923\right]=0.05 \mathrm{M}, \mathrm{RT}$.

\subsection{Screening of solvents as polar phase}

The extraction of $\mathrm{Nd}(\mathrm{III})$ from ethylene glycol was compared with different solvents that are immiscible with $n$-dodecane. Figure 11 indicates that extraction of $\mathrm{Nd}(\mathrm{III})$ is more efficient from ethylene glycol than from $N, N$-dimethylformamide (DMF) and methanol $\left(\mathrm{CH}_{3} \mathrm{OH}\right)$. In addition, ethylene glycol (EG) can be considered as best solvent from an environmental point of view, considering the non-volatile nature and high boiling point [44]. It is interesting to note that the extraction order in the solvents follows their acceptor number and dielectric constant [20]. The acceptor number (AN) is a measure of the electrophilic behavior of a solvent relative to $\mathrm{SbCl}_{5}$ [45]. The solvents considered in this study and their dielectric 
constant of solvents are listed in Table 3. The solvent with highest acceptor number showed the highest percentage extraction.

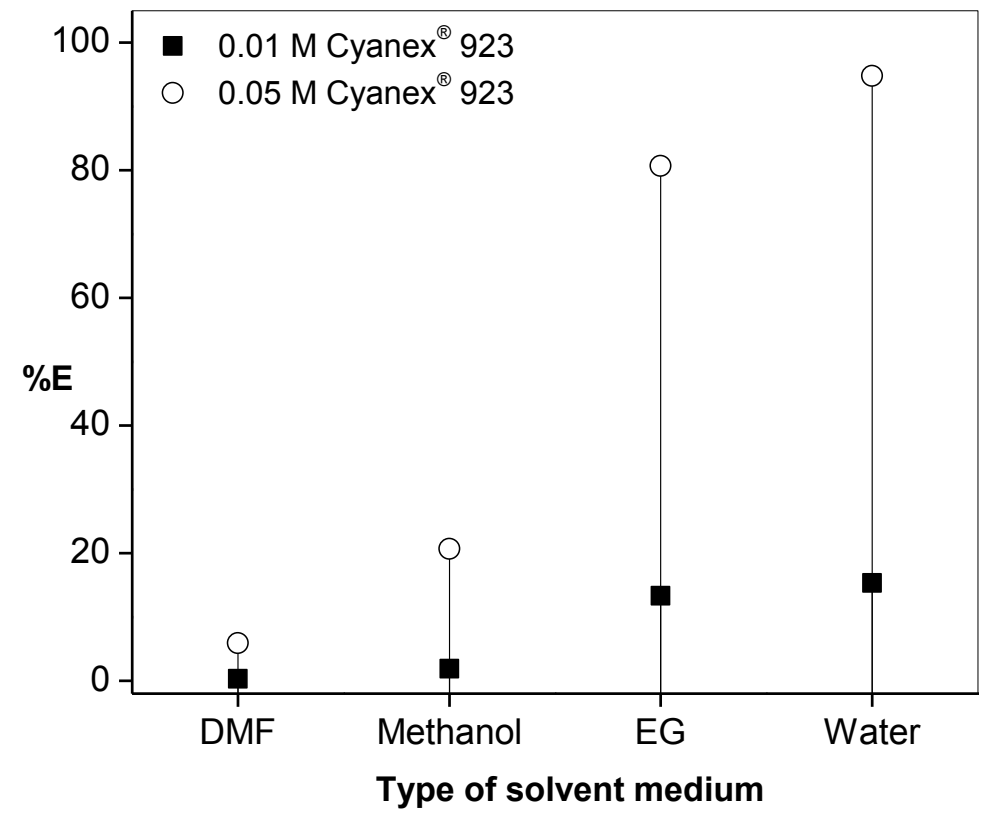

Figure 11. The extraction of $\mathrm{Nd}(\mathrm{III})$ from different solvent feed solutions by Cyanex ${ }^{\circledR} 923$. $[\mathrm{Nd}(\mathrm{III})]=6.7 \times 10^{-3} \mathrm{M}$ in ethylene glycol, $\left[\mathrm{LiNO}_{3}\right]=1 \mathrm{M}$.

Table 3. Acceptor number and dielectric constants of solvents

\begin{tabular}{lll}
\hline Solvent & Acceptor Number & Dielectric constant ${ }^{20}$ \\
\hline Water & 54.8 & 80.4 \\
EG & 42.8 & 37.0 \\
Methanol & 41.3 & 32.6 \\
DMF & 16 & 26.6 \\
\hline
\end{tabular}




\subsection{Influence of diluents}

The influence of the nature of different diluents on the extraction of $\mathrm{Nd}(\mathrm{III})$ from ethylene glycol by Cyanex ${ }^{\circledR} 923$ was studied (Figure 12). The physical properties of the diluent play an important role in the solvent extraction of metals. The extraction is higher using aliphatic diluents than aromatic diluents. Based on the experimental results, $n$-dodecane can be considered as the best diluent.

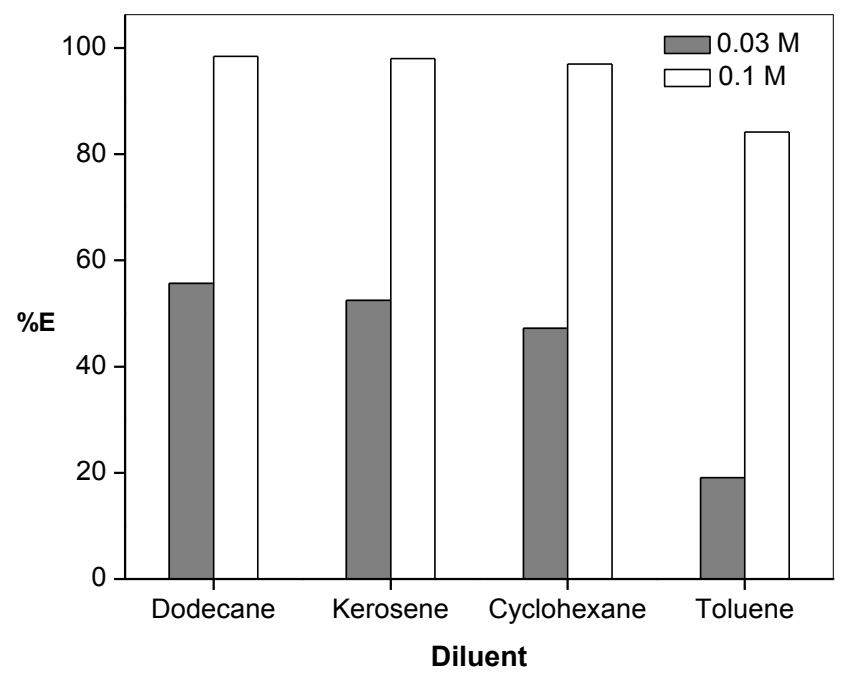

Figure 12. The influence of diluent on the extraction of $\mathrm{Nd}(\mathrm{III})$ by $\mathrm{Cyanex}^{\circledR} 923$. $[\mathrm{Nd}(\mathrm{III})]=$ $6.7 \times 10^{-3} \mathrm{M}$ in ethylene glycol, $\left[\mathrm{LiNO}_{3}\right]=1 \mathrm{M},\left[\mathrm{Cyanex}^{\circledR}{ }^{\circledR} 923\right]=0.03 \mathrm{M}$ and $0.1 \mathrm{M}, \mathrm{RT}$.

The performance of the ethylene glycol / $\left(n\right.$-dodecane + Cyanex $\left.{ }^{\circledR} 923\right)$ system was compared with that of the corresponding aqueous system, for several rare-earth ions. The extraction parameters for the two extraction systems were the same, except that water was the polar solvent in the aqueous system and ethylene glycol in the non-aqueous system. The 
concentration of each rare-earth ion was $(1.07 \pm 0.2) \times 10^{-3} \mathrm{M}$. The extractions were performed from mixture of different rare earths. The extraction of the rare-earth ions increases with increasing in their atomic number in both systems, but differences are observed for the two extraction systems (Figure 13). The extraction of the light rare earths is less efficient from ethylene glycol than from aqueous solutions. On the other hand, the extraction of heavy rare earths increases in ethylene glycol medium as a function of the atomic number, so that the separation of heavy rare earths from light rare earths is facilitated. For extraction of rare-earth nitrates from aqueous solution by Cyanex ${ }^{\circledR} 923$, the separation factor $\beta$ for neighboring heavy rare earths is virtually equal to 1.00 , so that no separation of mixtures of rare earths is possible. The separation factor of the $\mathrm{Dy}+\mathrm{Yb}$ pair over $\mathrm{La}+\mathrm{Ce}+\mathrm{Pr}+\mathrm{Nd}$ was found to be 54.5 at $0.03 \mathrm{M}$ Cyanex ${ }^{\circledR} 923$ in $n$-dodecane from ethylene glycol medium, whereas it was only 2.3 from aqueous solutions. This indicates that the ethylene glycol / $\left(n\right.$-dodecane + Cyanex $\left.{ }^{\circledR} 923\right)$ system can be used for group separations of the heavy rare earths from the light rare earths. 


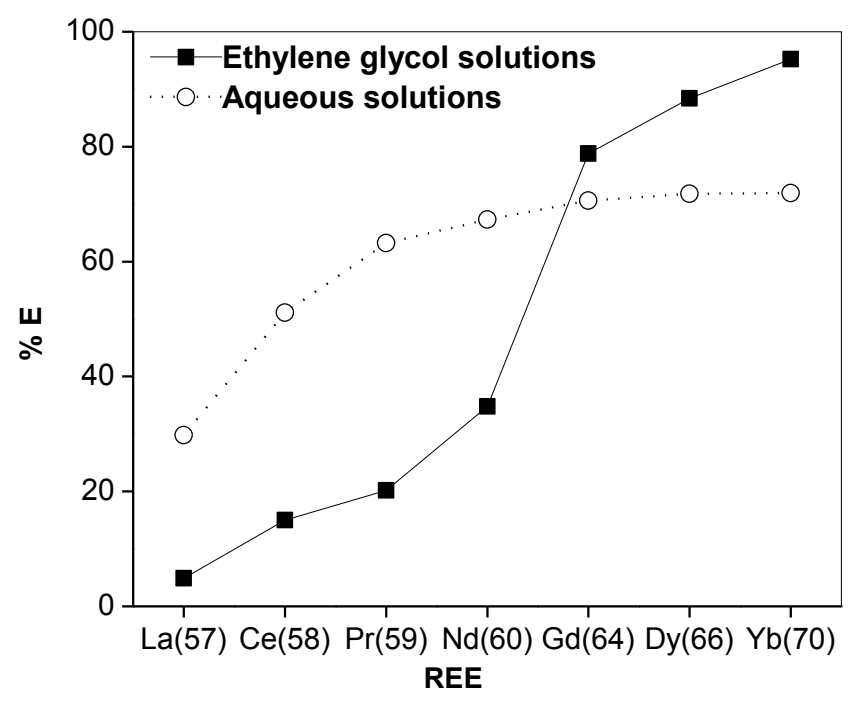

Figure 13. Comparison of extraction behavior of a mixture of trivalent rare-earth ions from aqueous solutions and from non-aqueous ethylene glycol solutions using $0.03 \mathrm{M}^{\text {Cyanex }}{ }^{\circledR}$ 923 in $n$-dodecane. $[\mathrm{RE}(\mathrm{III})]=1.07 \pm 0.2 \times 10^{-3} \mathrm{M}($ each $),\left[\mathrm{LiNO}_{3}\right]=1 \mathrm{M}, \mathrm{RT}$.

The influence of variation in the concentration of the extractant Cyanex ${ }^{\circledR} 923$ in the $n$ dodecane phase on the extraction efficiency was investigated. The concentration of Cyanex ${ }^{\circledR}$ 923 was varied between $0.01 \mathrm{M}$ and $0.1 \mathrm{M}$. Extraction from ethylene glycol medium was compared with extraction from aqueous solution (Figure 14). A first trend that can be observed is that the $\% E$ increases with increasing Cyanex 923 concentration, as expected. For extractions from aqueous solutions, the $\% E$ values for the different rare-earth ions are very similar (except for $\mathrm{La}(\mathrm{III})$ and $\mathrm{Ce}(\mathrm{III})$ ) so that separation of mixtures of rare-earth ions is impossible under these experimental conditions. For extraction from ethylene glycol, the different rare-earth ions show different $\% E$ and $D$ values at each of the Cyanex ${ }^{\circledR} 923$ concentrations investigated. 


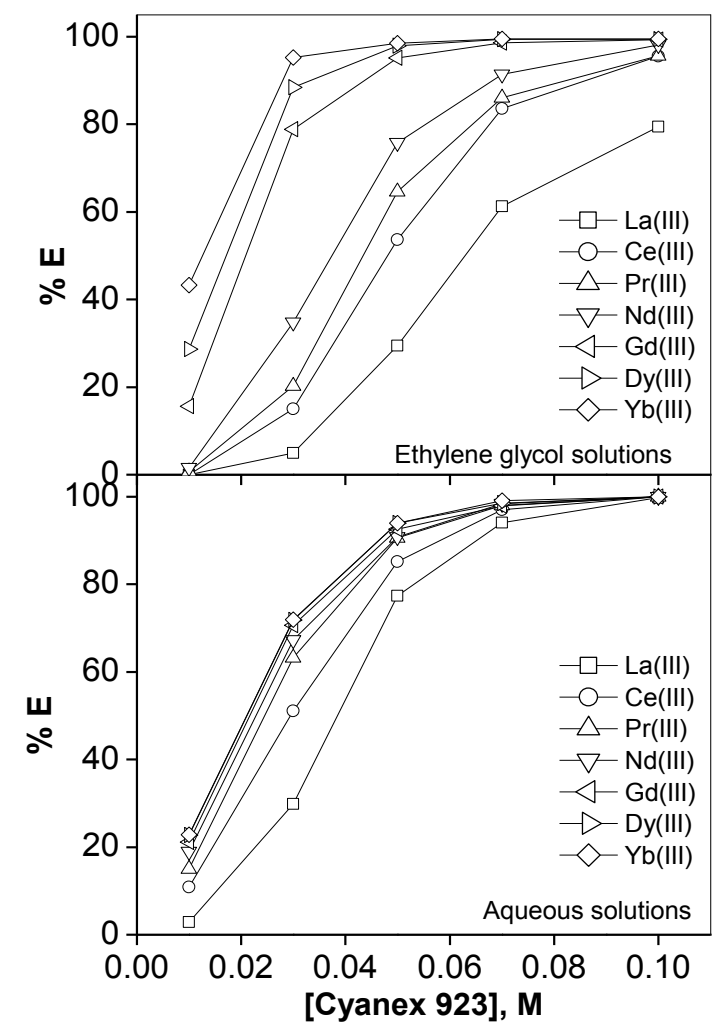

Figure 14. Influence of the Cyanex ${ }^{\circledR} 923$ concentration on the extraction of a mixture of trivalent rare-earth ions from aqueous solutions and non-aqueous ethylene glycol solutions. $[\mathrm{RE}(\mathrm{III})]=1.07 \pm 0.2 \times 10^{-3} \mathrm{M}($ each $)$ in $\mathrm{EG},\left[\mathrm{LiNO}_{3}\right]=1 \mathrm{M},\left[\mathrm{Cyanex}^{\circledR} 923\right]=0.01-0.1 \mathrm{M}$ in $n$-dodecane, RT.

\subsection{Separation of Dy(III) and Nd(III)}

The separation of binary mixtures of $\mathrm{Nd}(\mathrm{III})$ and $\mathrm{Dy}(\mathrm{III})$ in ethylene glycol was studied, with $\mathrm{Nd}(\mathrm{III})$ being a representative light rare earth and Dy(III) a representative heavy rare earth. In Figure 15 , the separation factors $\beta$ Nd,Dy are compared for aqueous and non-aqueous solutions 
(ethylene glycol) for different concentrations of Cyanex ${ }^{\circledR} 923$ and from solutions containing $1.07 \times 10^{-3} \mathrm{M}$ of $\mathrm{Nd}(\mathrm{III})$ and $.1 .07 \times 10^{-3} \mathrm{M}$ of Dy(III). This figure clearly shows that the separation factors are much larger for extraction from ethylene glycol than from aqueous solutions. In fact, no separation of $\mathrm{Nd}(\mathrm{III})$ and $\mathrm{Dy}(\mathrm{III})$ can be achieved by extraction from aqueous solution with Cyanex ${ }^{\circledR} 923$ under these conditions. Extractions from ethylene glycol solutions with three different concentrations $\left(1 \mathrm{gL}^{-1}, 5 \mathrm{~g} \mathrm{~L}^{-1}\right.$ and $10 \mathrm{~g} \mathrm{~L}^{-1}$ of each element $)$ of binary mixtures of $\mathrm{Nd}(\mathrm{III})$ and $\mathrm{Dy}(\mathrm{III})$ were studied as a function of the Cyanex ${ }^{\circledR} 923$ concentration (Figure 16). The separation factor of Dy(III) over $\mathrm{Nd}(\mathrm{III})$ is 24.6 from ethylene glycol for a Cyanex ${ }^{\circledR} 923$ concentration of $0.01 \mathrm{M}$, whereas the separation is only 1.2 for extraction under similar experimental conditions from aqueous solutions. It was not possible to calculate separation factor values for $C y a n e x^{\circledR} 923$ concentration of $0.1 \mathrm{M}$ since there is close to $100 \%$ extraction of both $\mathrm{Dy}(\mathrm{III})$ and $\mathrm{Nd}(\mathrm{III})$ under these condition. The separation efficiency depends both on the concentrations of the extractant and the metal ion. The maximum separation factors for solutions containing 1,5 and $10 \mathrm{~g} \mathrm{~L}^{-1}$ of metal ions were $25.1,13.0$ and 12.9 , respectively. These separation factors suggest that separation of binary $\mathrm{Nd}(\mathrm{III}) / \mathrm{Dy}(\mathrm{III})$ mixtures is possible by extraction from an ethylene glycol solution by Cyanex ${ }^{\circledR} 923$, even at industrially relevant concentrations of rare-earth salts of $10 \mathrm{~g} \mathrm{~L}^{-1}$. For the highest Cyanex ${ }^{\circledR} 923$ concentrations, it is not possible to calculate $D$ values and thereby separation factor $\beta$ Nd,Dy since there is $100 \%$ of extraction. This is due to the fact that in the presence of a large excess of extractant compared to the concentration of the rare-earth ions in the feed solution, there is little competition between the two ions for extraction by the extractant molecules so that even the least extractable ion is extracted in an appreciable amount. 


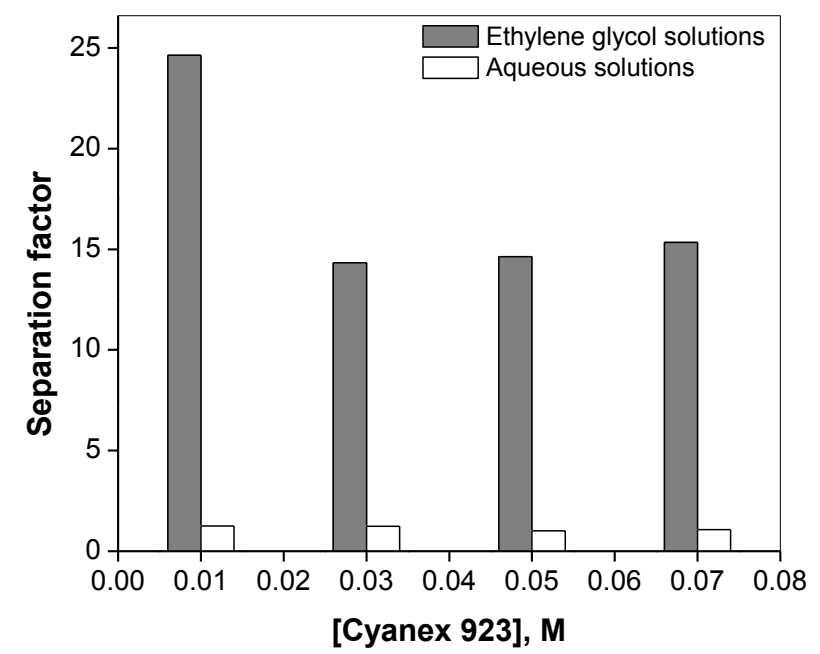

Figure 15. Comparison of the separation factors of Dy(III) over $\mathrm{Nd}(\mathrm{III})$ from aqueous solutions and non-aqueous ethylene glycol solutions for extraction by Cyanex ${ }^{\circledR} 923$ in $n$ dodecane.

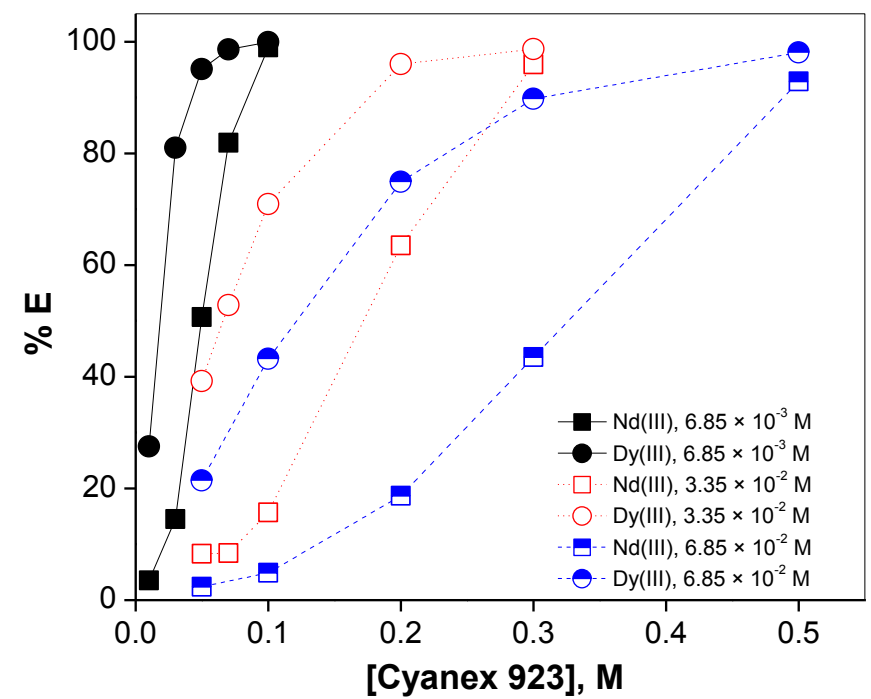

Figure 16. Influence of the Cyanex ${ }^{\circledR} 923$ concentration on the extraction of a binary mixture of $\mathrm{Nd}(\mathrm{III})$ and $\mathrm{Dy}(\mathrm{III})$ from ethylene glycol solutions at room temperature. 


\subsection{Stripping studies}

After extraction, the rare-earth could be stripped from the $n$-dodecane phase by addition of oxalic acid so that the rare-earth oxalates precipitated (precipitation stripping) [46]. Stripping of the loaded Cyanex ${ }^{\circledR} 923 / n$-dodecane phase was carried out using oxalic acid and water (Table 4). 100\% stripping was found with $0.01 \mathrm{M}$ oxalic acid and also with water.

Table 4. Stripping of $\mathrm{Nd}(\mathrm{III})$ from $\mathrm{Nd}(\mathrm{III})$ loaded 0.1 M Cyanex ${ }^{\circledR} 923$

\begin{tabular}{lllll|l}
\hline Oxalic acid, M & 0.01 & 0.05 & 0.1 & 0.5 & Water \\
\hline$\%$ Stripping & 100 & 100 & 100 & 100 & 100 \\
\hline
\end{tabular}

$[\mathrm{Nd}(\mathrm{III})]$ in loaded phase $=6.6 \times 10^{-3} \mathrm{M}$

\subsection{Recycling studies}

The reuse of 0.05 M Cyanex ${ }^{\circledR} 923 / n$-dodecane was studied for five extraction and stripping cycles. First, Cyanex ${ }^{\circledR}$ 923/n-dodecane was loaded with Nd(III) and then the loaded Cyanex ${ }^{\circledR}$ 923 was stripped with water. The extraction and stripping percentages corresponding to a single extraction and stripping cycle are $80 \%$ and $100 \%$, respectively. The spent Cyanex $^{\circledR}$ 923/n-dodecane was used for a second extraction/stripping cycle. The procedure was repeated for five cycles. The extraction percent of $\mathrm{Nd}(\mathrm{III})$ was remain unchanged $(80 \pm 2 \%)$ after five extraction cycles and stripping percent of $99 \pm 2 \%$ after 5 stripping cycles. This indicates the very good recycling capacity and stability of the extraction system. 


\section{Conclusions}

Solvent extraction with two mutually immiscible organic phases can offer advantages over conventional extraction from an aqueous phase to an immiscible organic phase as shown for the extraction of trivalent rare-earth ions from ethylene glycol solutions by the neutral extractant Cyanex ${ }^{\circledR} 923$ dissolved in $n$-dodecane. This extractant system performs better for the group separation of heavy rare earths from light rare earths than the corresponding conventional extraction system with an aqueous phase. Also the separation of binary mixtures of $\mathrm{Nd}(\mathrm{III})$ and $\mathrm{Dy}(\mathrm{III})$ are possible by this new solvent extraction system.

\section{ACKNOWLEDGMENTS}

This research was financially supported by the FWO-Flanders (research project G.0900.13 and postdoctoral fellowship to TVDH) and KU Leuven (projects GOA/13/008 and IOF-KP $\mathrm{RARE}^{3}$, and F+ postdoctoral fellowship to NKB). Cytec Industries (Canada) is acknowledged for a gift of samples of Cyanex ${ }^{\circledR} 923$ and Cyanex ${ }^{\circledR} 272$. The authors thank Daphne Depuydt for her assistance to the NMR measurements and analysis of NMR spectra. 


\section{REFERENCES}

[1] J. Rydberg, M. Cox, C. Musikas, G.R. Choppin (eds.), Solvent Extraction: Principles and Practice, $2^{\text {nd }}$ ed., Marcel Dekker, New York, 2004.

[2] Y. Marcus, Liquid extraction from molten salts. In Advances in Molten Salt Chemistry, Volume 1, Braunstein, J.; Mamantov, G.; Smith, G.P. (Eds.) Plenum Press: New York, 1971; pp 63-127.

[3] N. M. Isaac, P.R. Fields, D.M. Gruen, Solvent extraction of actinides and lanthanides from molten salts, J. Inorg. Nucl. Chem. 21 (1961) 152-168.

[4] R.V.J. Ammon, Die Verteilung einiger Kationen zwischen den unmischbaren flüssigen Phasen im System AlBr3-KBr, Inorg. Nucl. Chem. 28 (1966) 2569-2578.

[5] F.J. Smith, Distribution of $\mathrm{PdBr}_{2}, \mathrm{RhBr}_{3}$ and $\mathrm{RuBr}_{3}$ between the two immiscible liquid phases in the AlBr3-KBr system, J. Less-Common Met. 97 (1984) 21-26.

[6] Y. Aratono, E. Akatsu, Liquid-liquid extraction of several elements in the system of fused $\mathrm{Ca}\left(\mathrm{NO}_{3}\right)_{2} \cdot 4 \mathrm{H}_{2} \mathrm{O}$ and tri-n-butyl phosphate, J. Inorg. Nucl. Chem. 36 (1974) 1141-1146. [7] V.A. Maroni, C.E. Philbin, R.M. Yonco, Extraction of 3d transition metals from molten cesium-sodium-potassium/acetate eutectic into dodecane using organophosphorous ligands, Sep. Sci. Technol. 18 (1983) 1699-1713.

[8] K.R. Kim, D.H. Ahn, J.B. Shim, S. Paek, I.T. Kim, Y. Jung, Pyrochemical extraction analysis of an immiscible molten LiCl-KCl/Cd system, J. Radioanal. Nucl. Chem. 304 (2015) $329-335$.

[9] T. Kobayashi, An Assessment of the Multi-stage Counter Current Extraction of TRUs from Spent Molten Salt, into Liquid Metal, J. Nuclear Sci. Technol. 43 (2006) 819-823. 
[10] T. Koyama, T.R. Johnson, D.F. Fischer, Distribution of actinides in molten chloride salt/cadmium metal systems, J. Alloys Compds. 189 (1992) 37-44.

[11] S. Wellens, B. Thijs, C. Moller, K. Binnemans, Separation of cobalt and nickel by solvent extraction with two mutually immiscible ionic liquids, Phys. Chem. Chem. Phys. 15 (2013) 9663-9669.

[12] A. Rout, S. Wellens, K. Binnemans, Separation of rare earths and nickel by solvent extraction with two mutually immiscible ionic liquids, RSC Adv. 4 (2014) 5753-5758.

[13] M.R.S. Foreman, Progress towards a process for the recycling of nickel metal hydride electric cells using a deep eutectic solvent, Cogent Chem. 2 (2016) art. number 1139289. [14] E.M. Larsen, L.E. Trevorrow, The systems formed by zirconium and hafnium tetrachloride with acetonitrile and isoamyl ether, J. Inorg. Nucl. Chem. 2 (1956) 254-259. [15] T. M. Florence, Y.J. Farrar, Liquid-Liquid Extraction of Nickel with Long-chain Amines from Aqueous and Nonaqueous Halide Media, Anal. Chem. 40 (1968) 1200-1206. [16] A.R. Burns, R.W. Cattrall, The distribution of copper(II) between methanolic lithium chloride solutions and benzene solutions of bis(3,5,5-trimethylhexyl)ammonium chloride, J. Inorg. Nucl. Chem. 35 (1973) 2489-2496.

[17] J. A. Dean, J.B. Eskew, Solvent extraction with two immiscible organic solvents: separation of thallium(III), Anal. Lett. 4 (1971) 737-743.

[18] M. Matsui, T. Aoki, H. Enomoto, T. Shigematsu, Nonaqueous liquid-liquid extraction: extraction of zinc from ethylene glycol solution of chloride by trioctylphosphine oxide, Anal. Lett. 8 (1975) 247-255.

[19] W.M. Jackson, J.S. Drury, Miscibility of Organic Solvent Pairs, Ind. Eng. Chem. 51 (1959) 1491-1493. 
[20] C. Reichardt, T. Welton, Solvents and Solvent Effects in Organic Chemistry, Fourth Edition, Wiley-Interscience, Weinheim, 2011.

[21] H. Eckert, Auswahl von Lösungsmittelsystemen zur multiplikativen Verteilung, Chimia 8 (1954) 229-240.

[22] F. Xie, T.A. Zhang, D. Dreisinger, F. Doyle, A critical review on solvent extraction of rare earths from aqueous solutions, Miner. Eng. 56 (2014) 10-28.

[23] C.K. Gupta, N. Krishnamurthy, Extractive Metallurgy of Rare Earths, CRC Press, Boca Raton, FL (2004).

[24] A. Rout, K. Binnemans, Influence of the ionic liquid cation on the solvent extraction of trivalent rare-earth ions by mixtures of Cyanex 923 and ionic liquids, Dalton Trans. 44 (2015) 1379-1387.

[25] H. Tong, Y. Wang, W. Liao, D. Li, Synergistic extraction of Ce(IV) and Th(IV) with mixtures of Cyanex 923 and organophosphorus acids in sulfuric acid media, Sep. Purif. Technol. 118 (2013) 487-491.

[26] C. Tunsu, C. Ekberg, M. Foreman, T. Retegan, Studies on the Solvent Extraction of Rare Earth Metals from Fluorescent Lamp Waste Using Cyanex 923, Solvent Extr. Ion Exch. 32 (2014) 650-668.

[27] Z. Zhang, H. Li, F. Guo, S. Meng, D. Li, Synergistic extraction and recovery of Cerium(IV) and Fluorin from sulfuric solutions with Cyanex 923 and di-2-ethylhexyl phosphoric acid, Sep. Purif. Technol. 63 (2008) 348-352.

[28] E. Dziwinski, J. Szymanowski, Composition of CYANEX ${ }^{\circledR}$ 923, CYANEX ${ }^{\circledR}$ 925, CYANEX $^{\circledR} 921$ and TOPO, Solv. Extr. Ion Exch. 16 (1998) 1515-1525.

[29] Cytec Industries Inc., Cyanex ${ }^{\circledR} 923$ Extractant (datasheet), 2008. https://www.cytec.com/sites/default/files/datasheets/SPT-032-D.pdf 
[30] K.V. Klementev, Package "VIPER (visual processing in EXAFS researches) for windows.”, Nucl. Instr. Meth. Phys. Res. A 448 (2000) 299-301.

[31] M. Newville, EXAFS analysis using FEFF and FEFFIT, J. Synchrotron Radiat. 8 (2001) 96-100.

[32] N. V. Thakur, Separation of rare earths by solvent extraction, Miner. Process. Extr. Metall. Rev. 21 (2000) 277-306.

[33] T. Sekine, Y. Hasegawa, Solvent extraction chemistry: Fundamentals and applications, Marcel Dekker, New York, 1977.

[34] V. Gutmann, Empirical parameters for donor and acceptor properties of solvents, Electrochim. Acta 21 (1976) 661-670.

[35] Y.A. El-Nadi, Effect of diluents on the extraction of praseodymium and samarium by Cyanex 923 from acidic nitrate medium, J. Rare Earths 28 (2010) 215-220.

[36] J.R. Ferraro, The nature of the nitrate in the TBP solvates $\mathrm{M}\left(\mathrm{NO}_{3}\right)_{3} \cdot 3 \mathrm{TBP}$, $\mathrm{M}\left(\mathrm{NO}_{3}\right)_{4} \cdot 2 \mathrm{TBP}$ and $\mathrm{MO}_{2}\left(\mathrm{NO}_{3}\right)_{2} \cdot 2 \mathrm{TBP}$, J. Inorg. Nucl. Chem. 10 (1959) 319-322.

[37] M.L.P. Reddy, R.L. Varma, T.R. Ramamohan, S.K. Sahu, V. Chakravortty, Cyanex 923 as an extractant for trivalent lanthanides and yttrium, Solvent Extr. Ion Exch. 16 (1998) $795-812$.

[38] I. Persson, P. Angelo, S.D. Panfilis, M. Sandstrom, L. Eriksson, High-energy X-ray absorption spectroscopy: A new tool for structural investigations of lanthanoids and third-row transition elements, Chem. Eur. J. 17 (2008) 3056-3066.

[39] J. Legendziewicz, M. Guzik, J. Gliński, K. Jerie, A. Baranowski, A. Kochel, Application of spectroscopy and positron annihilation methods in studies of the gel-glasses materials, J. Alloys Compds. 451 (2008) 172-178. 
Hamakawa, F. Mizukami, Extraordinary dissolution of coordination polymer, $\mathrm{La}\left[\mathrm{Fe}(\mathrm{CN})_{6}\right] \cdot 5 \mathrm{H}_{2} \mathrm{O}$, in ethylene glycol/water mixed solvent and structural determination of dissolved species, Inorg. Chem. Commun. 11 (2008) 323-325.

[41] A. Bowden, S.J. Coles, M.B. Pitak, A.G.W. Platt, Complexes of Lanthanide Nitrates with Tri-Tert-Butylphosphine Oxide, Inorg. Chem. 51 (2012) 4379-4389.

[42] G.R. Choppin, A. Morgenstern, Thermodynamics of solvent extraction, Solvent Extr. Ion Exch. 18 (2000) 1029-1049.

[43] J. Shibata, M. Sano, S. Nishimura, Extraction of metal ions from mixed aqueousorganic media with liquid-liquid extraction and ion exchange resin, Proceedings of the International Solvent Extraction Conference 1990 (ISEC 90), edited by T. Sekine, Elsevier, 1992, pp. 1169-1174.

[44] R.K. Henderson, C. Jiménez-González, D.J.C. Constable, S.R. Alston, G.G.A. Inglis, G. Fisher, J. Sherwood, S.P. Binks, A.D. Curzons, Expanding GSK's solvent selection guide: embedding sustainability into solvent selection starting at medicinal chemistry, Green Chem. 13 (2011) 854-862.

[45] U. Mayer, V. Gutmann, W. Gerger, The acceptor number - a quantitative empirical parameter for the electrophilic properties of solvents, Monatsh. Chem. 106 (1975) 12351257.

[46] T. Vander Hoogerstraete, B. Blanpain, T. Van Gerven, K. Binnemans, From NdFeB magnets towards the rare-earth oxides: a recycling process consuming only oxalic acid, RSC Adv. 4 (2014) 64099-64111. 